\title{
Indo-U.S. Workshop on Advanced Techniques for Microstructural Characterization Promotes Collaboration
}

The Indo-U.S. Workshop on Advanced Techniques for Microstructural Characterization held in Bombay, January 11-14, 1988 achieved its aims of sharing scientific information and developing collaborative projects between Indian and U.S. scientists. Nine proposals for collaborative projects were submitted for consideration at the end of the workshop.

The workshop was organized under the Indo-U.S. Science and Technology Agreement by the government of India's Department of Science and Technology and by the U.S. Office of Naval Research. Prof. T.R. Anantharaman (Benaras Hindu University, Varanasi, India) and Dr. Chandra S. Pande (Naval Research Laboratory, Washington, D.C.) chaired the workshop. Dr. R. Krishnan (Naval Chemical and Metallurgical Laboratory, Bombay) and Dr. Om P. Arora (David Taylor Naval Shipyard, Annapolis, MD) served as cochairs.

A keynote speech by Prof. S. Ranganathan (Department of Metallurgy, Indian Institute of Science), nine technical sessions, and a poster session offered an interdisciplinary, expansive, and high quality scientific treatment of topics by experts in the field. (Topics and speakers are listed at the end of this article.) Commenting on the meeting, one U.S. participant remarked that "half the world's top experts in materials characterization are here."

In remarks on the workshop's mutual benefits, chairman Chandra Pande said, "One pleasant suprise to many U.S. participants was the consistently high quality of presentations from the Indian side." "India," he continued, "has the third largest pool of scientists in the world, many of them trained in European and U.S. universities. In several areas of science, such as superconductivity and materials characterization, they have made outstanding contributions." On the other hand, said Pande, "Indian scientists, many of them working in isolation, also became aware of recent developments in the United States."

The workshop will serve as a model for another one on "Interfaces" to be held in November 1988. The U.S. organizers for the upcoming meeting will be Chandra S. Pande and David Smith (IBM, Yorktown Heights, NY). The Indian organizer will be Prof. S. Ranganathan.

Proceedings of the workshop, Advanced Techniques for Microstructural Characterization, edited by T.R. Anantharaman and R. Krishnan, are available from Trans Tech Publications Ltd., Old Post Road, Brookfield, VT 05036 U.S.A., and P.O. Box 10CH-4711 Aedermannsdorf, Switzerland.

\section{Technical Program}

Session I-Transmission Electron Microscopy at Atomic Resolution, R. Gronsky (Lawrence Berkeley Lab); XRDT Characterization, R.W. Armstrong (Univ. of Maryland); Scanning Tunneling Microscopy: Theory, Technique and Application, R.J. Colton (U.S. Naval Research Lab)

Session II-Analytical Electron Microscopy, D.B. Williams (Lehigh Univ.); Some Aspects of Analytical Electron Microscopy, T.R. Ramachandran (Indian Institute of Technology); Digital Imaging Systems for Electron Microscopy, K. Ramamurti (Alpha Prime Inc.); Electron Energy Loss Spectroscopy of Semiconductors, K.L. Chopra (Indian Institute of Technology).

Session III-Convergent Beam Diffraction, I.A. Eades (Univ. of Illinois); Studies in Convergent Beam Electron Diffraction, D. Banerjee (Defense Metallurgical Research Lab, India); Electron Channeling for Materials Characterization, D.C. Joy (Univ. of Tennessee).

Session IV-Surface and Interface Studies in Metals Using AES and XPS, A. Joshi Lockheed R\&D); X-Ray Photoabsorption and X-Ray Photoelectron Spectroscopies and the Mixed Valence Phenomenon, B.D. Padalia (Indian Institute of Technology); Chemical Identification of Solid Surfaces, Auger Electron Spectroscopy, M.S. Hegde (Indian Institute of Science); Chemical Analysis on an Atomic Scale Using the FIM/Atom Probe, S.S. Brenner (Univ. of Pittsburgh).

Session V-High Resolution X-Ray Diffractometry, K. Lal (National Physical Lab, India); Applications of Synchrotron Radiation to Materials Science, M. Kuriyama (U.S. National Bureau of Standards);
Use of Synchrotron Radiation and Neutrons in Materials Characterization, B.A. Dasannacharya and A.S. Sequeira (Bhabha Atomic Research Center); Precision Measurement of Microplasticity, Computer-Aided Rocking Curve Analysis, R.N. Pangborn (Pennsylvania State Univ.).

Session VI-Low Energy Interfaces in Thin Film Structures, M.F. Chisholm and D.A. Smith (IBM T.J. Watson Research Center); Channeling Enhanced Microanalysis, K.M. Krishnan (Lawrence Berkeley Lab); Atom Location Studies on Crystal Surface Using UHV X-Ray Standing Waves, J.R. Patel (AT\&T Bell Labs).

Session VII-Small Angle Neutron Scattering, C.S. Pande, B.E. Rath, M.A. Ima, and C.L. Vold (U.S. Naval Research Lab); Elemental Analysis Using Neutron Beam Techniques, R.F. Fleming (U.S. National Bureau of Standards); and a special lecture by C.N.R. Rao.

Session VIII-Rutherford Backscattering Spectrometry and Ion Channeling, A Jain (Bhabha Atomic Research Center); Characterization of Defects in Metals, Positron Annihilation, K.P. Gopinathan (Indira Gandhi Center for Atomic Research); Characterization of Ultrafine Particles, J. Kumar (Indian Institute of Technology).

Session IX-High Resolution Transmission Electron Microscopy of Semiconductor Interfaces and Surfaces, J.M. Gibson (AT\&T Bell Labs); Transmission Electron Microscopy of Ceramics, L.W. Hobbs (Massachusetts Institute of Technology); Diffusion and Reaction Studies in Several VLSI Materials, D. Gupta (IBM T.J. Watson Research Center); Use of TEM in Phase Transformation Studies, S. Banerjee (Bhabha Atomic Research Center).

For information about the upcoming workshop on interfaces, contact:

$$
\begin{gathered}
\text { C.S. Pande } \\
\text { Physical Metallurgy Branch } \\
\text { Naval Research Lab } \\
\text { Code } 6325 \\
\text { Materials Science and Technology Division } \\
\text { Washington, DC 20375-5000 } \\
\text { Telephone: (202) 767-2744 } \\
\text { S. Ranganathan } \\
\text { Department of Metallurgy } \\
\text { Indian Institute of Science } \\
\text { Bangalore } 560012 \text { india }
\end{gathered}
$$

